\title{
Effect of sequencing batch reactor (SBR)/granular activated carbon (GAC) bed and membrane hybrid system for simultaneous water reuse and membrane fouling mitigation
}

\author{
Hyeongok Lee, Kilsoo Hyun ${ }^{\dagger}$ \\ School of Constructional Disaster Prevention and Environmental Eng., Kyungpook National University, 2559 Gyeongang-daero, Sangju, 37224, Korea
}

\begin{abstract}
The objectives of this study are to assess the potential of an activated and granular sludge (AS and GS) sequencing batch reactor (SBR)/granular activated carbon (GAC) coupled with a membrane for achieving reclamation and reuse of real mixed wastewater and to evaluate the feasibility of the configured systems for achieving membrane fouling mitigation. A better performance of membrane filtration (MF) having lower membrane fouling was observed at both higher agitation velocity and lower permeate flux. Despite a twice shorter hydraulic retention time (HRT) than that of the AS-SBR/MF configured system, the performances of the GS-SBR/MF system without and with a GAC bed as a pretreatment for the MF process achieved higher efficiencies than those of the AS-SBR system for organics and nutrient removal and higher flux in the MF. The addition of a GAC filter after SBR processes was more effective in mitigating membrane fouling due to effective foulant removal. These results indicate that the GS-SBR as an alternative process for the AS-SBR or the addition of a GAC bed after the SBR process is needed to obtain the reusable water with good quality and to improve the fouling rate and filtration time of the MF process.
\end{abstract}

Keywords: Activated and granular sludge, GAC, Membrane fouling, Real mixed wastewater, Sequencing batch reactor

\section{Introduction}

Regarding stable operation and a stringent effluent guideline, an activated sludge (AS) process coupled with a membrane in rural areas has been upgraded to treat a mixed wastewater effectively. Three kinds of the mixed wastewater generated on the rural area can be identified: domestic wastewater (DW), black water (BLW: feces and urine), and landfill leachate (LL), which have high organics and nutrient concentrations with nonbiodegradable and heavy metal components [1, 2]. A higher quality of the effluent from membrane bioreactors (MBRs) treating the mixed wastewater has been often difficult to obtain effectively through the AS process. The MBR using AS has resulted in a rapid decline of permeate flux, which results in a reduction in productivity of the MBR and increase in maintenance and operational costs [3]. Various approaches have been employed to mitigate membrane fouling including inorganic flocculants and granular materials addition [4-5].

Therefore, a conventional bioreactor needs to be a high-rate reactor through an increase in the biomass level, such as biogranulation and particle-supported biofilm. A MBR using granular sludge (GS) has been developed to overcome the challenges of a higher-quality effluent and membrane fouling in conventional MBRs [6]. Compared with the AS, a round GS is compact and strong in structure with the ability to settle rapidly and a high capacity for biomass retention [7]. A sequencing batch reactor (SBR) technology using GS as a pretreatment for membrane filtration (MF) is under development to enhance the performance of simultaneous organics and nutrient removal and to mitigate membrane fouling in conventional MBRs [8]. The other alternative pretreatment seems to be a granular activated carbon (GAC) filter, which provides both adsorption and biofiltration through biological activated carbon (BAC). BAC has two functions of biodegradability and filtration due to the growth and formation of a layer of biomass (biofilm) on the rough porous surfaces of GAC particles [9]. The BAC bed also has the advantage of being a compact reactor due to a high biofilm surface area, high biomass concentration, and minimum
This is an Open Access article distributed under the terms of the Creative Commons Attribution Non-Commercial License (http://creativecommons.org/licenses/by-nc/3.0/) which permits unrestricted non-commercial use, distribution, and reproduction in any medium, provided the original work is properly cited.

Copyright (C) 2021 Korean Society of Environmental Engineers
Received December 25, 2019 Accepted March 21, 2020

${ }^{\dagger}$ Corresponding author

Email: kshyun@knu.ac.kr

Tel: +82-54-530-1442 Fax: 82-54-530-1449

ORCID: 0000-0002-2824-319X 
excess sludge production, resulting in stable operation and good protection against toxicants. The BAC utilizing the combination of adsorption and biodegradable techniques also provides an attractive pre-filtration for achieving both high organics removal and low membrane fouling rates $[9,10]$. Previous studies reported that the submerged type of membrane module into a GS reactor and the addition of activated carbon into MBRs have been studied to improve both a membrane fouling mitigation and an organic and nutrient removal [6-10]. The submerged MBRs have achieved a low fouling rate for short filtration time, whereas they have achieved a high fouling rate for a long filtration time, resulting in a high increase of suspended solids through granules break-up due to an agitation in MBR [11, 12]. In this study, hybrid systems combining GS with and without GAC bed followed by a membrane were configured to remove an effective potential foulants regarding a long filtration time and a low fouling rate [13-16]. Thus, The purposes of this study are to deduce the appropriate operating conditions of AS and GS-SBR coupled with a membrane using synthetic wastewater and to assess both the potential for reclamation and reuse of real mixed wastewater and the feasibility of mitigating membrane fouling by the AS- and GS-SBR/GAC as a pretreatment of MF.

\section{Material and Methods}

\subsection{Experimental Apparatus and Materials}

The bench- and pilot-scale plants for this study consisted of four systems: AS-SBR/MF, GS-SBR/MF, AS-SBR/GAC/MF, and GS-SBR/GAC/MF. The plants for this research (Fig. 1) consisted of a raw wastewater storage tank, two SBRs for AS and GS reactors (each hydraulic retention time (HRT) $<6 \mathrm{~h}$ ), two GAC beds, two $\mathrm{MF}$ reactors, and an effluent storage tank. The SBR and GAC beds were fabricated using four transparent acrylic cylinders. Air diffusers were placed at the bottoms of the SBR for aeration and the GAC beds for backwashing. The SBRs (total volume: $2 \mathrm{~L}$, working volume: $1 \mathrm{~L}$ ) were operated by means of an AS and a GS concept. A complete cycle of the SBR operation comprised filling (5 min), aeration/non-aeration (100-240 $\mathrm{min} / 60-90 \mathrm{~min})$, settling (10-30 min), and discharging (5 min) steps. Influent was added from the top of the reactor, and air was introduced from the bottom at an air flowrate of $2-4 \mathrm{~L} / \mathrm{min}$. Membrane filtration experiments were carried out to input mixed liquors taken from AS-SBR and GS-SBR processes into membrane filters. For biofiltration experiments to reduce the residual contaminants in the effluent from SBRs, the GAC bed (working volume: $2 \mathrm{~L}$, diameter: $5 \mathrm{~cm}$, height: $120 \mathrm{~cm}$ ) was packed up to $60 \mathrm{~cm}$ with GAC media (effective size: $1.5 \mathrm{~mm}$; Samchully, Korea). The empty bed contact time (EBCT) of the GAC bed ranged from 0.6 to $1.2 \mathrm{~h}$. The MF process using a dead-end stirred filtration (DSF) cell (Amicon 8400, Millipore, USA) consisted of raw water and effluent storage tanks, an electric balance, a digital pressure gauge, a computer, and a cylindrical vessel (working volume: $200 \mathrm{~mL}$ ) equipped with a porous support on which the membrane had been placed [17]. Flat sheet membranes (polyvinylidene di-fluoride, PVDF) with a pore size of $0.22 \mu \mathrm{m}$ and surface area of $41.8 \mathrm{~cm}^{2}$ were used, and a new membrane was used for each filtration run. Stirring rates of 200-1,000 rpm were selected to determine the effect of the agitation rate on membrane fouling by sludge components. The permeate weight was measured during the filtration process with an electronic balance. The sampling-time interval was varied from $30 \mathrm{~s}$ to 5 min according to the permeation rate. The effluent flow and transmembrane pressure (TMP) were monitored with an electric balance and a digital pressure gauge, respectively. Data on the permeate mass and pressure were collected every minute, and the results were stored on a computer.

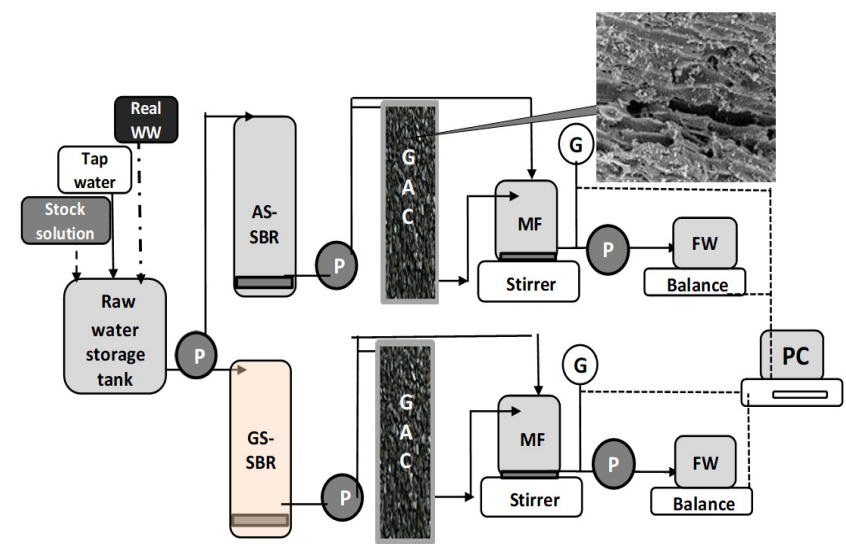

Fig. 1. Schematic of configured system of AS- and GS-SBR/GAC/MF (WW: wastewater; G: digital pressure gauge; P: pump; FW: finished water).

Table 1. Characteristics of SBRs/GAC/MF Configured Systems

\begin{tabular}{|c|c|c|}
\hline & PropertiesUnit process & Value \\
\hline \multirow{3}{*}{ Sequencing batch reactor } & - Reactor volume (L) & 2 \\
\hline & - MLSS (mg/L): AS-SBR/GS-SBR & $<3500 /<7000-10000$ \\
\hline & - HRT (h): AS-SBR/GS-SBR(filling/aeration/settling/discharging) & $6 /<4(0.08 / 2.67-5.0 / 0.17-0.50 / 0.08)$ \\
\hline \multirow{3}{*}{ GAC bed } & - Bed size (m): diameter/height (acrylic column) & D $0.045 /$ H 1.1 \\
\hline & - GAC packed depth (m) with effective size of $1.5 \mathrm{~mm}$ & 0.6 \\
\hline & - Empty bed contact time (min) & $<30$ \\
\hline \multirow{4}{*}{ Membrane filter } & - Membrane module/material with pore size of $0.22 \mu \mathrm{m}$ & Flat-sheet/PVDF \\
\hline & - Reactor working volume (L): dead-end stirring cell & 0.2 \\
\hline & - Permeate flux $\left(\mathrm{L} / \mathrm{m}^{2} \cdot \mathrm{h}\right)$ & $<60$ \\
\hline & - Stirring rate (rpm) of dead-end stirring cell & $<1,000$ \\
\hline
\end{tabular}




\subsection{Influent Characteristics and Analyses}

Synthetic and real wastewaters as raw water were used during this experiment. The influent qualities of synthetic wastewater used for AS- and GS-SBR experiments were as follows: water temperature $20 \pm 0.5^{\circ} \mathrm{C}, \mathrm{pH} 6.7 \pm 0.4$, chemical oxygen demand (COD) $300 \pm 10.5 \mathrm{mg} / \mathrm{L}$, total nitrogen $(\mathrm{T}-\mathrm{N}) 17.43 \pm 1.56 \mathrm{mg} / \mathrm{L}$, and total phosphorus (T-P) $3.25 \pm 0.18 \mathrm{mg} / \mathrm{L}$. The synthetic wastewater was composed of 150-350 mg/L of glucose (Daejung, Korea), 80 $\mathrm{mg} / \mathrm{L}$ of magnesium sulfate heptahydrate $\left(\mathrm{MgSO}_{4}, 7 \mathrm{H}_{2} \mathrm{O}\right.$; Samchun, Korea), $70 \mathrm{mg} / \mathrm{L}$ of ammonium chloride $\left(\mathrm{NH}_{4} \mathrm{Cl}\right.$; Daejung, Korea), $20 \mathrm{mg} / \mathrm{L}$ of potassium dihydrogen phosphate $\left(\mathrm{KH}_{2} \mathrm{PO}_{4}\right.$; Yakuri, Japan). The additional compositions for GS-SBR were $150 \mathrm{mg} / \mathrm{L}$ of sodium acetate $\left(\mathrm{CH}_{3} \mathrm{COONa}\right.$, Oriental, Korea) and $1.0 \mathrm{ml} / \mathrm{L}$ of trace element solution: $(20 \mathrm{mg} / \mathrm{L}$ of ferrous sulfate heptahydrate ( $\mathrm{FeSO}_{4}, 7 \mathrm{H}_{2} \mathrm{O}$; Daejung, Korea), $50 \mathrm{mg} / \mathrm{L}$ of copper sulfate pentahydrate $\left(\mathrm{CuSO}_{4}, 5 \mathrm{H}_{2} \mathrm{O}\right.$; Oriental, Korea), $3 \mathrm{mg} / \mathrm{L}$ of boric acid $\left(\mathrm{H}_{3} \mathrm{BO}_{3}\right.$; Oriental, Korea), $50 \mathrm{mg} / \mathrm{L}$ of manganese sulfate monohydrate ( $\mathrm{MnSO}_{4}, \mathrm{H}_{2} \mathrm{O}$; Yakuri, Japan), $80 \mathrm{mg} / \mathrm{L}$ of zinc chloride heptahydrate ( $\mathrm{ZnCl}_{2}, 7 \mathrm{H}_{2} \mathrm{O}$; Daejung, Korea), $50 \mathrm{mg} / \mathrm{L}$ of cobalt (II) dichloride hexahydrate $\left(\mathrm{CoCl}_{2}, 6 \mathrm{H}_{2} \mathrm{O}\right.$; Sanchun, Korea)). A stock solution was diluted with tap water. The bioreactor and bed were initially inoculated with AS obtained from the aeration tank of a real sewage treatment plant. Initial concentration of mixed liquor suspended solid (MLSS) in both reactors was $500 \pm 50 \mathrm{mg} / \mathrm{L}$. The characteristics of real mixed wastewater (DW 67.0\%: BLW 25.5\%: LL 7.5\%) were as follows: water temperature: $22.6 \pm 1.8^{\circ} \mathrm{C}, \mathrm{pH}: 6.8 \pm 0.5,134.8$ $\pm 3.5 \mathrm{mg}$ TOC/L, $32.00 \pm 1.60 \mathrm{mg} \mathrm{T}-\mathrm{N} / \mathrm{L}, 3.40 \pm 0.13 \mathrm{mg} \mathrm{T}-\mathrm{P} / \mathrm{L}$, and $42.5 \pm 8.4 \mathrm{mg} \mathrm{SS} / \mathrm{L}$. This wastewater was pre-treated by means of gravity settling to reduce the concentration of solids. Samples of influent and effluent from each process and system during the experiments were collected and analysed for the following parameters: $\mathrm{pH}$, dissolved oxygen (DO), SS, T-N, and T-P. DO concentration and $\mathrm{pH}$ were measured with standard probes (Hach, USA). Analyses of organics, nutrients, and SS were performed according to Standard Methods [18]. Nitrogen and phosphorus were measured with a spectrophotometer (Varian-Cary 50, Australia). Total organic carbon (TOC) was quantified using a TOC analyser (Shimadzu TOC-5000, Japan).

\section{Results and Discussion}

\subsection{Performance of AS- and GS-SBR/MF Systems}

\subsubsection{Effects of SBR performance on contaminants removal}

Fig. 2 shows the performance results of activated and granular sludge processes using synthetic wastewater during one cycle of SBRs. DO concentration was $3.5 \pm 0.7 \mathrm{mg} / \mathrm{L}$ during aeration phase prior to non-aeration phase. During 30 to 60 days of operation in steady-state condition, the removal efficiencies of GS-SBR with shorter HRT $(3 \mathrm{~h}$ ) were $89.1 \pm 5.2 \%$ for COD, $70.2 \pm 6.2 \%$ for $\mathrm{T}-\mathrm{N}$, and $78.1 \pm 5.1 \%$ for T-P, while the removal efficiencies of AS-SBR with longer HRT (6 h) after the operating day 60 were $87.2 \pm 2.1 \%$ for COD, $62.8 \pm 2.1 \%$ for $\mathrm{T}-\mathrm{N}$, and $69.5 \pm 2.3 \%$ for T-P. One-half of the removal efficiency during one cycle was achieved within 60 to $80 \mathrm{~min}$ for the AS-SBR and 40 to $50 \mathrm{~min}$ for the GS-SBR after start-up. After 45 days of operation, the COD,

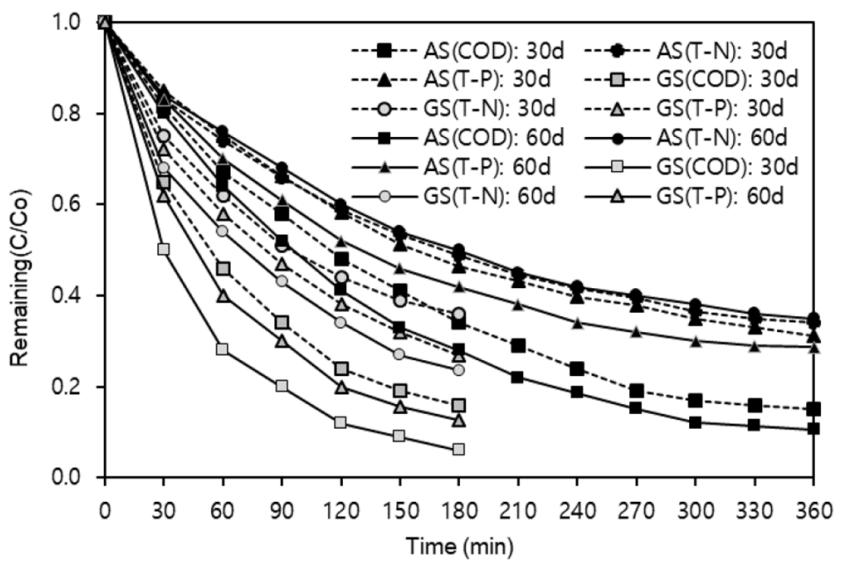

Fig. 2. Comparative result of activated and granular sludge processes performances on COD and nutrient removal during one cycle of SBRs.

T-N and T-P removal efficiencies of GS-SBR process had achieved good average effectiveness of more than $90 \%, 70 \%$, and $80 \%$, respectively. The organics and nutrient removal efficiencies of the GS-SBR were $10-20 \%$ higher than those of the AS-SBR. This was due to higher reaction capacity (biodegradation and uptake) of GS than that of AS [9]. Compared with AS, high nitrogen removal of GS results in a high formation of anoxic and anaerobic area in the inner part of the granule, which will improve the denitrification process $[3,19,20]$. In particular, the GS has the stratified structure with an oxic zone near the granule surface, an anaerobic zone at the granule core, and a transient anoxic zone between the aerobic and anaerobic zones [6, 21, 22]. Granules of around $1 \mathrm{~mm}$ were predominant at the top of the reactor; however, larger granules of up to $3 \mathrm{~mm}$ were also found at the bottom of the reactor. It also had good settling ability and a high capacity for biomass retention. The average settling velocity (SV) of the granules ranged from $28.3-32.8 \mathrm{~m} / \mathrm{h}$, which was slightly lower than that reported by Tay et al. (30-35 m/h) [23]. Contrary to the fast settling of GS, effluent SS (25-40 mg/L) from the GS was quite high. The above results indicate that the performance of the GS-SBR achieves shorter HRT and higher effluent quality than those of the AS-SBR despite high organic loadings. For AS-SBR process with low MLSS level $(3,200 \pm 300 \mathrm{mg} / \mathrm{L})$, both the longer HRT and higher solid retention time than that of GS-SBR process (MLSS 6,800 \pm 500 $\mathrm{mg} / \mathrm{L}$ ) are required to enhance the nitrogen removal efficiency by providing nitrification and denitrification in the reactor and to improve membrane fouling by reducing foulants, such as dissolved and particulate organic matters. These considerations indicate that the GS-SBR process as well as the AS-SBR process requires post-treatment processes to meet the national standard for wastewater reuse and reclamation [24].

3.1.2 Performance Characteristics of SBRs coupled with Membrane Batch filtration experiments of MF using a DSF cell were carried out to determine the optimal operating conditions for the MF process alone regarding agitation velocity and permeate flux (Figs. 3-5). During batch filtration experiments, a new membrane was used for each filtration run. Figs. 3 and 4 show the characteristics of 
both organic and nutrient removal and the filterability of MF process with the change of agitation velocity and permeate flux. A raw water used for this study was the mixed effluent from AS- and GS-SBR (COD $30 \pm 1.5 \mathrm{mg} / \mathrm{L}$, T-N $3.73 \pm 0.32 \mathrm{mg} / \mathrm{L}$, T-P 0.68 $\pm 0.04 \mathrm{mg} / \mathrm{L}$, SS $27.2 \pm 2.5 \mathrm{mg} / \mathrm{L})$. As shown in Fig. 3(a) and (b), when increasing the agitation velocity from 0 to $1000 \mathrm{rpm}$ at a constant permeate flux of $20 \mathrm{~L} / \mathrm{m}^{2} . h$, the removal of COD and nutrient showed a slightly decrease trend $(<20 \%)$ with increasing agitation velocity on the membrane surface (Fig. 3(a)). On the other hand, the TMP developing rates at agitation velocities of 200, 400, and $1000 \mathrm{rpm}$ were $17.6 \%, 21.6 \%$, and $32.0 \%$ lower than those without agitation (Fig. 3(b)). These results indicate that an appropriate agitation velocity in this study is $200 \mathrm{rpm}$ regarding both contaminants removal and membrane fouling mitigation. In particular, the profiles of TMP build-up with agitation velocity increased sharply within $1 \mathrm{~min}$ of the start of filtration and reached a pseudo-steady state after 5 min of operation, after which TMP increased considerably slowly as the agitation velocity increased. This result suggests that membrane fouling needs to be minimized by creating a high hydraulic shear force near the membrane surface to prevent cake layer formation [23]. However, an application of a high-strength agitation for GS-SBR has an ineffective on the mitigation of TMP build-up due to an increase of suspended solids through granules break-up [17]. This indicates that the agitation strength of GS-SBR regarding granulation and granules break-up is needed to be lower than that of AS-SBR

Fig. 4(a) and (b) show the MF performance results under different permeate fluxes using the mixed effluent from the SBRs. During batch experiments of MF with agitation velocity of $200 \mathrm{rpm}$, applied permeate fluxes for each filtration run were 10, 20, 40, and 60 $\mathrm{L} / \mathrm{m}^{2}$.h. The removal efficiencies of COD and nutrient of MF showed a slightly decrease trend with increasing permeate flux (Fig. 4(a)). In particular, the higher COD and T-P removal rate than that of T-N was observed. This was due to the removal of particulate COD and T-P by high reaction capacity (biodegradation and uptake) of biofilm on membrane surface [9]. This indicates that a lower permeate flux for stable biofilm growth is needed to achieve a high nitrogen removal as well as organics and phosphorus [25, 26]. On
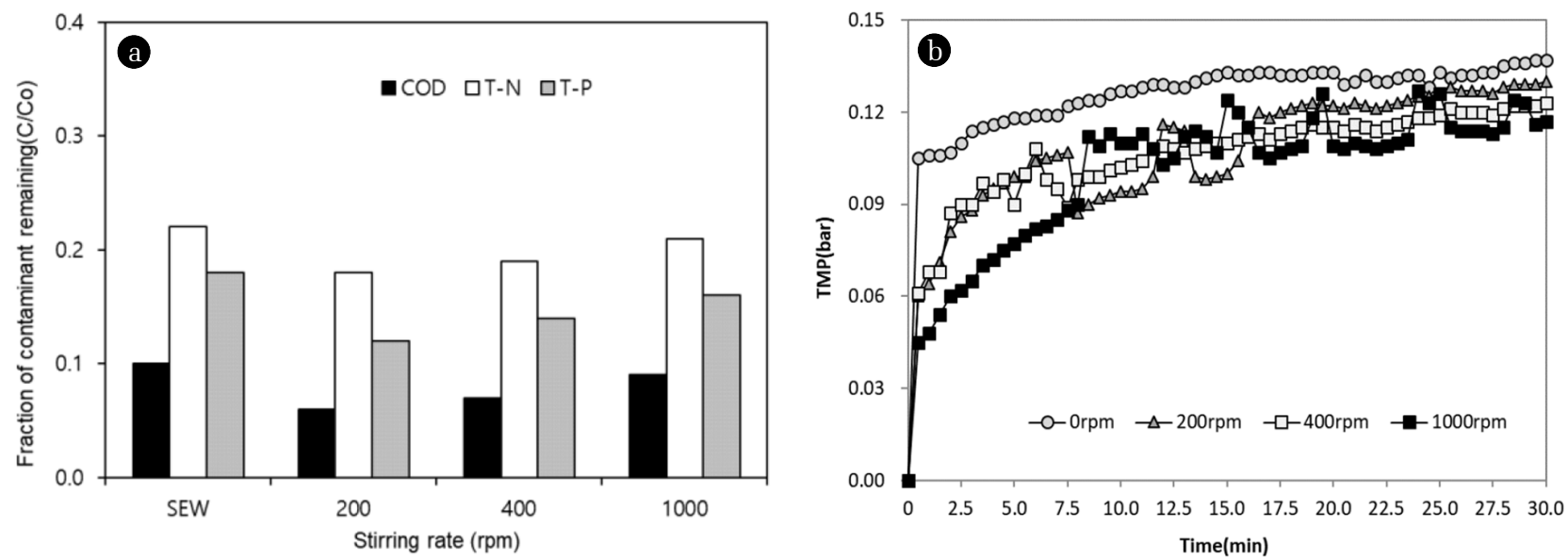

Fig. 3. Influence of agitation on contaminant removal and TMP development in MF process using the mixed effluent from the SBRs. (a) Agitation vs contaminant removal, (b) Agitation vs TMP build-up.
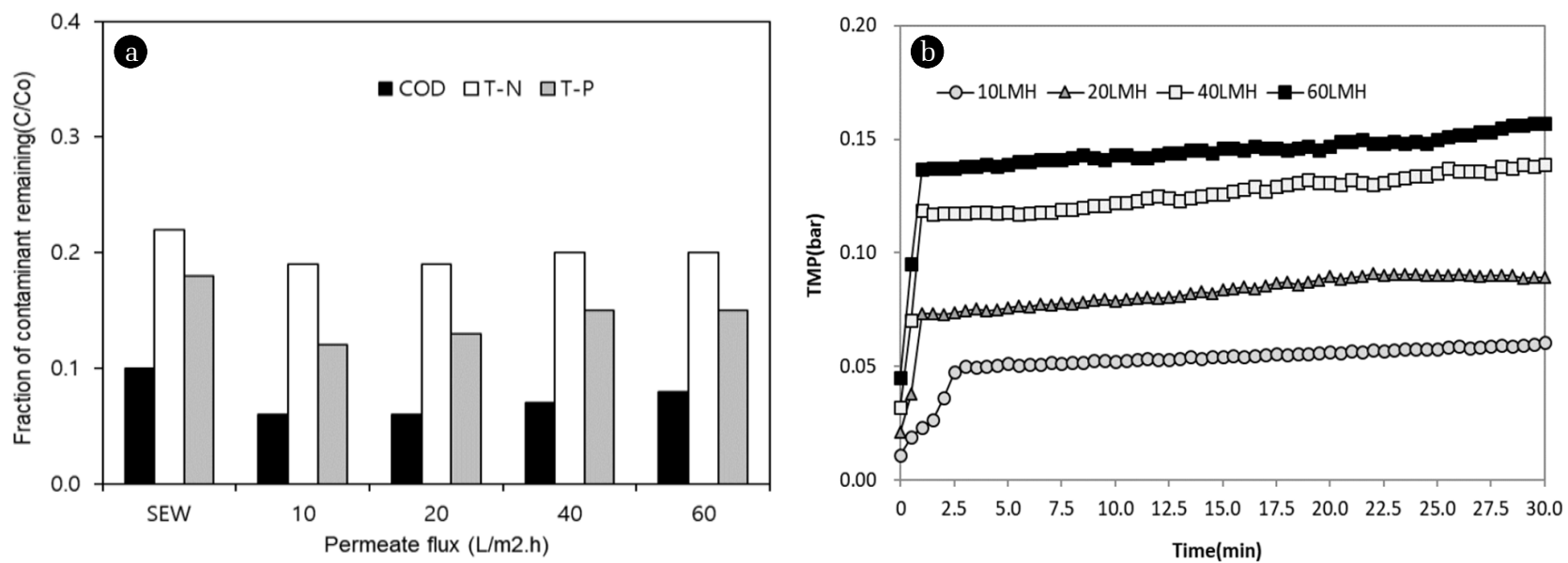

Fig. 4. Influences of permeate flux on contaminant removal and TMP development in MF process using the mixed effluent from the SBRs. (a) Permeate flux vs contaminant removal, (b) Permeate flux vs TMP build-up. 

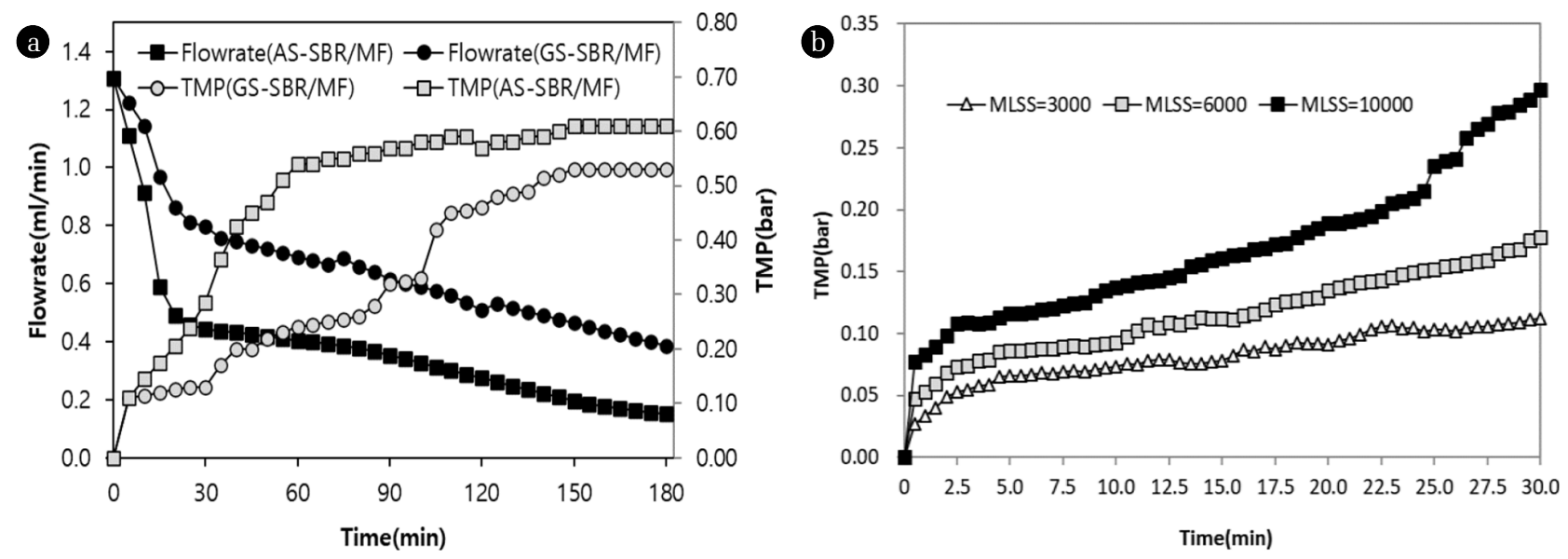

Fig. 5. Filtration performance of MF processes using activated and granular sludge as a pretreatment. (a) Flowrate vs TMP, (b) MLSS vs TMP for GS-SBR.

the other hand, the TMP developing rates at each permeate flux of 20,40 , and $60 \mathrm{~L} / \mathrm{m}^{2}$.h were $13.2 \%, 41.5 \%$, and $63.3 \%$ higher than that of a permeate flux of $10 \mathrm{~L} / \mathrm{m}^{2}$.h (Fig. 4(b)). A considerably fast increase of TMP was due to both smaller pore size of membrane and suspended solids increase by agitation [17, 24]. These results indicate that an appropriate permeate flux is less than $20 \mathrm{~L} / \mathrm{m}^{2} . \mathrm{h}$ regarding both contaminants removal and membrane fouling mitigation. In particular, the profiles of TMP build-up at permeate fluxes of 10 and $>20 \mathrm{~L} / \mathrm{m}^{2}$.h reached a pseudo-steady within 5 and $1 \mathrm{~min}$ of the start of filtration, respectively. $70-80 \%$ of total TMP build-up developed within 1 min at the filtration time due to the dominant effect of pore blocking on permeate flux only at the beginning of filtration as the cake had not formed yet; however, compared with the whole filtration time, the process was very short. In addition, an increase in permeate flux and filtration time can result in both short-term rapid TMP build-up due to pore blocking and cake formation and a long-term gradual TMP rise due to cake compaction and irreversible fouling [27]. The pore-blocking phenomenon can be reduced or avoided by selecting proper uniform distributions of particle diameter and membrane size as well as appropriate permeate flux and agitation [17, 24].

Fig. 5 shows the comparative results of the filterability of MF process using the effluents from AS- and GS-SBR. Batch experiments of MF process were conducted at constant permeate flux and agitation velocity of $20 \mathrm{~L} / \mathrm{m}^{2} . \mathrm{h}$ and $200 \mathrm{rpm}$, which were the optimal operating conditions obtained from the above results. For the influence of AS and GS on the fouling of MF (Fig. 5 (a)), the GS-SBR/MF system at a constant TMP of 0.05 bar achieved 31.4\% higher flowrate than that of the AS-SBR/MF system. On the other hand, the GS-SBR/MF system at a constant permeate flux of $20 \mathrm{~L} / \mathrm{m}^{2} . h$ achieved 31.3\% lower TMP build-up than that of the AS-SBR/MF system. This was due to the lower organics and solid concentration of the effluent from the GS-SBR than that of the AS-SBR. In particular, biogranulation in the GS-SBR process seemed to result in a decrease in the protein extracellular polymeric substance (EPS) known as a foulant in the conventional MBR because a certain amount of EPS is consumed for the formation and stability of the granules under aerobic conditions [28, 29]. Fig. 5(b) shows the influence of MLSS level on the fouling of MF. When applied MLSS concentrations of 3,000, 6,000, and 10,000 $\mathrm{mg} / \mathrm{L}$ for the GS-SBR followed by $\mathrm{MF}$ with a constant permeate flux of $20 \mathrm{~L} / \mathrm{m}^{2} . \mathrm{h}$, TMP developing rates of MF process at 6,000 and 10,000 $\mathrm{mg} \mathrm{MLSS} / \mathrm{L}$ in the GS-SBR were $29.3 \%$ and $51.8 \%$ higher than that at $3000 \mathrm{mg} \mathrm{MLSS} / \mathrm{L}$ within 30 min of membrane operation. However, the TMP developing rate of MF process at 10,000 mg MLSS/L in GS-SBR was twice as high as that at $<6,000 \mathrm{mg}$ MLSS, which indicates that MLSS concentration in the GS-SBR should be properly controlled to mitigate membrane fouling.

\subsection{Comparative Evaluation of AS/MF System and GS-SBR/ GAC/MF System Performance}

The performances of the SBR/GAC/MF configured systems and the real AS/MF system were evaluated regarding the reuse of wastewater and the mitigation of membrane fouling using real mixed wastewater. The real AS/MF system (HRT: $6.5 \pm 0.1 \mathrm{~h}$, capacity: $\left.20,000 \mathrm{~m}^{3} / \mathrm{d}\right)$ consisted of anaerobic/anoxic/aerobic AS $\left(\mathrm{A}_{2} \mathrm{O}-\mathrm{AS}\right)$ reactor (MLSS 3,000 $\pm 200 \mathrm{mg} / \mathrm{L}$ ). The HRTs of the configured systems were $6.3 \pm 0.1 \mathrm{~h}$ for the AS-SBR/MF, $3.5 \pm 0.2 \mathrm{~h}$ for the GS-SBR/MF, $6.5 \pm 0.1 \mathrm{~h}$ for the AS-SBR/GAC/MF, and 3.7 $\pm 0.1 \mathrm{~h}$ for the GS-SBR/GAC/MF. Batch experiments of MF process were carried out at a constant permeate flux and agitation velocity of $20 \mathrm{~L} / \mathrm{m}^{2}$.d and $200 \mathrm{rpm}$. The influent characteristics of the SBRs and $\mathrm{A}_{2} \mathrm{O}$ processes using real mixed wastewater were $134 \pm 3.5$ $\mathrm{mg}$ TOC/L, $32.0 \pm 1.60 \mathrm{mg} \mathrm{T}-\mathrm{N} / \mathrm{L}$, and $3.40 \pm 0.13 \mathrm{mg} \mathrm{T}-\mathrm{P} / \mathrm{L}$. The $\mathrm{DO}$ and $\mathrm{pH}$ level ranges in both bioreactors were $3.2 \pm 5$ $\mathrm{mg} / \mathrm{L}$ and $6.9 \pm 0.3$, which resulted in effective substrate reduction and nitrification [25]. The effluent from the real $\mathrm{A}_{2} \mathrm{O}$ process $(\mathrm{pH}$ $6.9 \pm 3$, TOC $14.6 \pm 3.5$, T-N $8.42 \pm 1.65$, and T-P $0.72 \pm 0.13$ $\mathrm{mg} / \mathrm{L}$ ) was used as an influent of GAC and MF. During a month of operation in the steady-state condition (Fig. 6(a)), the removal efficiencies of TOC, T-N, and T-P were $72.1 \pm 5.1 \%$, $65.2 \pm 2.8 \%$, and $72.1 \pm 2.6 \%$ by the $\mathrm{A}_{2} \mathrm{O}-\mathrm{AS} / \mathrm{MF}$ system, $92.1 \pm 5.2 \%, 76.1$ $\pm 2.7 \%$, and $82.2 \pm 2.8 \%$ by the GS-SBR/MF system, $92.8 \pm 3.8$, $81.6 \pm 2.8$, and $83.7 \pm 3.3 \%$ by the $\mathrm{A}_{2} \mathrm{O}-\mathrm{AS} / \mathrm{GAC} / \mathrm{MF}$ system, and $94.5 \pm 3.5 \%, 84.6 \pm 2.5 \%$, and $89.5 \pm 2.7 \%$ by the GS-SBR/GAC/MF 

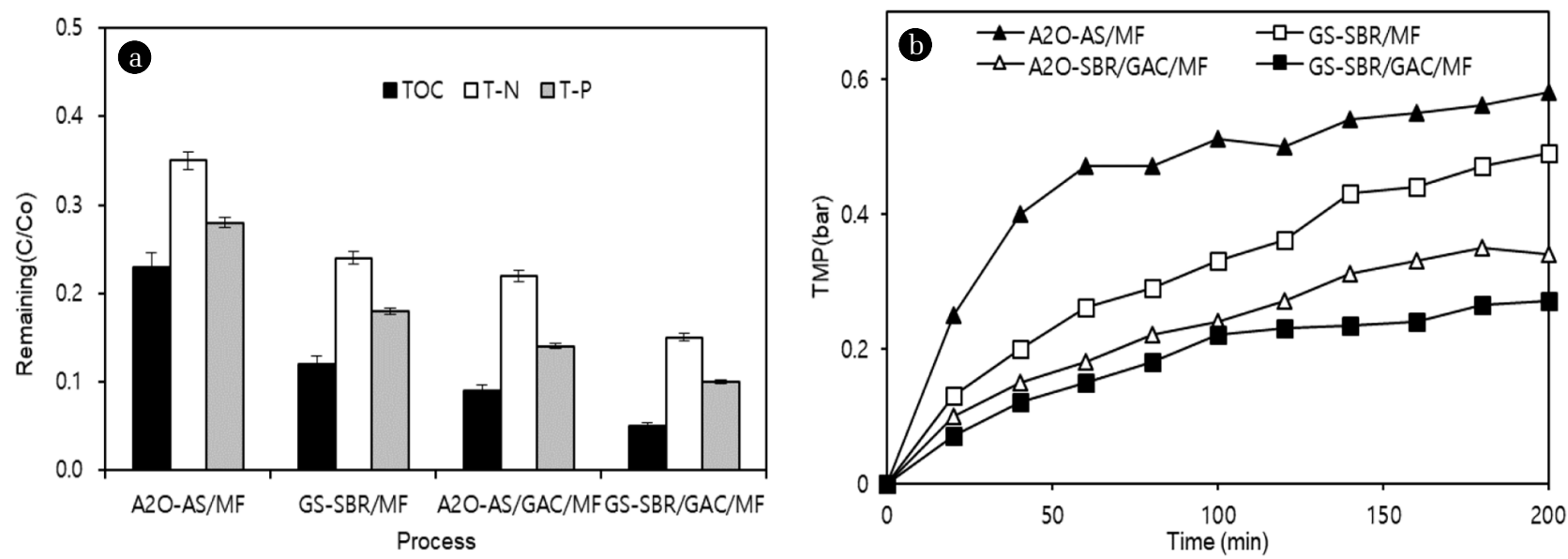

Fig. 6. Comparative results of configured system performance for real mixed wastewater treatment. (a) Contaminant removal by each process, (b) TMP build-up by each process.

system, respectively. The configured system with GAC bed showed higher efficiencies than that without GAC bed. The removal efficiencies of the GS-SBR/MF and $\mathrm{A}_{2} \mathrm{O}-\mathrm{AS} / \mathrm{GAC} / \mathrm{MF}$ systems continuously increased due to the growth of both granules in the GS-SBR and biofilm in the GAC bed with operation time, whereas the $\mathrm{A}_{2} \mathrm{O}-\mathrm{AS} / \mathrm{MF}$ system showed a limited removal efficiency, which resulted in lower biomass level in the AS-SBR than that in the GS-SBR due to a limited food to microorganisms $(\mathrm{F} / \mathrm{M})$ ratio in the AS-SBR [9]. On the contrary, excessive granule and biofilm growth in the GAC bed presented problems, such as the reduction of transfer flux, increase of fluid resistance, and corrosion inside the biofilm [26]. This indicates that it is necessary to maintain an appropriate sludge level (MLSS $<6,000 \mathrm{mg} / \mathrm{L}$ ) in both the GS-SBR and GAC bed. As mentioned above, despite a twice shorter HRT than that of the $\mathrm{A}_{2} \mathrm{O}-\mathrm{AS}$ system, the efficiencies of the GS-SBR/GAC system without the membrane process for TOC and nutrient removal were 43.6-53.3\% higher than those of the $\mathrm{A}_{2} \mathrm{O}-\mathrm{AS}$ system. The GS-SBR/GAC system alone was able to reduce the concentrations of pollutants to within acceptable limits for the application of non-potable water reuse except a few pollutants, such as particulate and microbial components. The performance of the MF process combined with the GS-SBR/GAC system for post-filtration achieved good removal results of $>90 \%$ for soluble nutrients as well as nonsoluble fractions, such as SS and particulate organics. Fig. 6(b) shows the comparative performance of the configured systems on membrane fouling mitigation. The GS-SBR/MF, $\mathrm{A}_{2} \mathrm{O}-\mathrm{AS} / \mathrm{GAC} / \mathrm{MF}$, and GS-SBR/GAC/MF systems achieved lower (24.5\%, 45.5\%, $52.3 \%)$ TMP build-up than that of the $\mathrm{A}_{2} \mathrm{O}-\mathrm{AS} / \mathrm{MF}$ system. Compared with the AS-SBR, a lower TMP build-up of the effluent from the GS-SBR resulted in lower both SS and dissolved organics due to the sludge granulation and the formation of high biomass in the GS-SBR [5]. Also, the introduction of GAC bed prior to the MF achieved a considerable low TMP build-up than that without the GAC. This is due to both the adsorption of dissolved organics and the biofiltration of SS by the GAC bed. High biomass due to both sludge granulation in the GS-SBR and the biofilm formation on the surface of GAC occurred through their simultaneous adsorption of non-biodegradable matter and the oxidation of biodegradable contaminants in a single reactor [30,31]. On the other hand, the permeability of the MF was almost constant due to the effective removal of EPS by the GS and BAC bed [28, 32, 33]. However, agitation in the GS-SBR with the operation time resulted in a relatively high effluent biomass concentration. This indicates that the GAC bed after GS-SBR treatment plays an important role in the stable treatment of the post-membrane filter [34]. Consequently, the combination of the GS-SBR/GAC system with post-MF was appropriate for stable operation due to membrane fouling mitigation as well as the reclamation and reuse of real mixed wastewater [34].

\section{Conclusions}

This study investigated to assess both the potential for reclamation and reuse of real mixed wastewater and the feasibility of mitigating membrane fouling by the AS- and GS-SBR/GAC as a pretreatment of MF. Results showed that a better MF performance with lower membrane fouling was observed at higher agitation velocity and lower permeate flux. Despite a twice shorter HRT than that of the AS-SBR/MF configured system, the performances of the GS-SBR/MF system without and with the GAC bed as a pretreatment for the MF process achieved higher efficiencies (27.3-32.1\%) than those of the AS-SBR system for organics and nutrient removal and a higher flux in the MF. The addition of the GAC filter after SBR processes was more effective in mitigating membrane fouling due to effective foulant removal through biofiltration. The removal efficiency of the combined GS-SBR/GAC system regarding dissolved and particulate foulants was higher (43.6-53.3\%) than that of the $\mathrm{A}_{2} \mathrm{O}-\mathrm{AS}$ system. These results indicate that the GS-SBR as an alternative process to the AS-SBR or the addition of the GAC bed after the SBR process is needed to obtain good-quality reusable water and to improve the fouling rate and filtration time of the MF process.

\section{Acknowledgment}

This article was presented at the 2019 International Desalination 
Workshop (IDW2019) held on 28-30 August 2019, Jeju, Korea.

\section{Author Contributions}

H.L. (Lecture, Ph.D) conducted most of the experiments and wrote the first draft of the paper. K.H. (professor) provided the research approach of all the experiment. All authors revised the paper and agreed on the final version of the paper.

\section{References}

1. Park CH, Hong SW, Chung TH, Choi YS. Performance evaluation of pretreatment processes in integrated membrane system for wastewater reuse. Desalination 2010;250:673-676.

2. Bodzek M, Lobos-Moysa E, Zamorowska M. Removal of organic compounds from municipal landfill leachate in a membrane bioreactor. Desalination 2006;198:16-23.

3. Zhou J, Yang F, Meng F, An P, Wang D. Comparison of membrane fouling during short-term filtration of aerobic granular sludge and activated sludge. J. Environ. Sci. 2007;19:1281-1286.

4. Wang ZW, Ma JX, Tang CY, Kimura K, Wang QY, Han XM. Membrane cleansing in membrane reactors: a review. J. Membr. Sci. 2014;468:276-307.

5. Park J, Yamashita N, Tanaka H. Membrane fouling control and enhanced removal of pharmaceuticals and personal care products by coagulation-MBR. Chemosphere 2018:197:467-476.

6. Iorhemen OT, Hamza RA, Sheng Z, Tay JH. Submerged aerobic granular sludge membrane bioreactor (AGMBR): Organics and nutrients (nitrogen and phosphorus) removal. Bioresour. Technol. Rep. 2019;6:260-267.

7. Adva SS, Lee DJ, Lai JY. Intergeneric coaggregation of strains isolated from phenol degrading aerobic granules. Appl. Microbiol. Biotechnol. 2008;79:657-661.

8. Iorhemen OT, Hamza RA, Sheng Z, Tay JH. Submerged aerobic granular sludge membrane bioreactor (AGMBR): Organics and nutrients (nitrogen and phosphorus) removal. Bioresour. Technol. Rep. 2019;6:260-267.

9. Tammaro M, Salluzzo A, Perfetto R, Lancia A. A comparative evaluation of biological activated carbon and activated sludge processes for the treatment of tannery wastewater. J. Environ. Chem. Eng. 2014;2:1445-1455.

10. Chinu KJ, Johir AH, Vigneswaran S, Shon HK, Kandasamy J. Biofilter as pretreatment to membrane based desalination: Evaluation in terms of fouling index. Desalination 2009;247: 77-84.

11. Guo WS, Vigneswaran S, Ngo HH, Kandasamy J, Yoon S. The role of a membrane performance enhancer in a membrane bioreactor: a comparison with other submerged membrane hybrid systems. Desalination 2008:231:305-313.

12. Meng F, Yang F, Shi B, Zhang H. A comprehensive study on membrane fouling in submerged membrane bioreactors operated under different aeration intensities. Sep. Purif. Technol. 2008;59:91-100.

13. Zhou Y, Pijuan M, Yuan Z. Development of a 2-sludge, 3-stage system for nitrogen and phosphorus removal from nutrient-rich wastewater using granular sludge and biofilms. Water Res. 2008;42:3207-3217.

14. Tay JH, Yang P, Zhuang WQ, Tay STL, Pan ZH. Reactor performance and membrane filtration in aerobic granular sludge membrane bioreactor. J. Membr. Sci. 2008;304:24-32.

15. Voutchkov N. Consideration for selection of seawater filtration pretreatment system. Desalination 2010;261:354-364.

16. Monnot M, Laborie S, Cabassud C. Granular activated carbon filtration plus ultrafiltration as pretreatment to seawater desalination lines: Impact on water quality and UF fouling. Desalination 2016;383:1-11.

17. Wang Z, Chu J, Zhang X. Study of a cake model during stirred dead-end microfiltration. Desalination 2007;217:127-138.

18. APHA, AWWA, and WEF. Standard Methods for the Examination of Water and Wastewater. 20th ed. Washington, D.C: American Public Health Association; 1998.

19. Li X, Gao F, Hua Z, Du G, Chen J. Treatment of synthetic wastewater by a novel MBR with granular sludge developed for controlling membrane fouling. Sep. Purif. Technol. 2005; 46(1-2):19-25.

20. Yuan X, Gao D. Effect of dissolved oxygen on nitrogen removal and process control in aerobic granular sludge reactor. J. Hazard. Mater. 2010;178:1041-1045.

21. Qin L, Liu Y, Tay JH. Denitrification on poly- $\beta$-hydroxybutyrate in microbial granular sludge sequencing batch reactor. Water Res. 2005;39:1503-1510.

22. Wang J, Wang X, Zhao Z, Li J. Organics and nitrogen removal and sludge stability in aerobic granular membrane bioreactor. Appl. Microbiol. Biotechnol. 2008;79:679-685.

23. Tay JH, Liu QS, Liu Y. Characteristics of aerobic granules grown on glucose and acetate in sequential aerobic sludge blanket reactors. Environ. Tech. 2002;23:931-936.

24. Thanh BX, Visvanathan C, Aim RB. Characterization of aerobic granular sludge at various organic loading rates. Process Biochem. 2009;44:242-245.

25. Kubin K, Kraume M, Dorau W. Investigation of nitrogen removal in a cascaded membrane bioreactor. Water Sci. Technol. 2002;46:241-247.

26. Fleischer JE, Broderick TA, Daigger GT, Fonseca AD, Holbrook $\mathrm{RD}$, Murthy SN. Evaluation of membrane bioreactor process capabilities to meet stringer effluent nutrient discharge requirement. Water Environ. Res. 2005;7:162-178.

27. Hong SP, Bae TH, Tak TM, Hong S, Randall A. Fouling control in activated sludge submerged hollow fiber membrane bioreactor. Desalination 2002;143:219-228.

28. Li ZH, Kuba T, Kusuda T. The influence of starvation phase on the properties and the development of aerobic granules. Enzyme Microb. Technol. 2006;38:670-674.

29. Lin H, Zhang M, Wang F, et al. A critical review of extracellular polymeric substances (EPSs) in membrane bioreactors: characteristics, roles in membrane fouling and control strategies. J. Membr. Sci. 2014;460:110-125.

30. Hong SP, Bae TH, Tak TM, Hong S, Randall A. Fouling control in activated sludge submerged hollow fiber membrane bioreactor. Desalination 2002;143:219-228.

31. Ma BC, Lee YN, Park JS, et al. Correlation between dissolved oxygen concentration, microbial community and membrane 
permeability in a membrane bioreactor. Process Biochem. 2006;41:1165-1172.

32. Leiknes T, Odegaard $\mathrm{H}$. The development of a biofilm membrane bioreactor. Desalination 2007;202:135-143.

33. Ahn YT, Kang ST, Chae SR, Lee CY, Bae BU, Shin HS. Simultaneous high-strength organic and nitrogen removal with combined anaerobic upflow bed filter and aerobic membrane bioreactor. Desalination 2007;202:114-121.

34. Sanchez AS, Garrido JM, Mendez R. A comparative study of tertiary membrane filtration of industrial wastewater treated in a granular and a flocculent sludge SBR. Desalination 2010;250:810-814. 